Published in final edited form as:

Addiction. 2004 April ; 99(4): 472-481.

\title{
Smoking and the Five-Factor Model of Personality
}

\author{
Antonio Terracciano and Paul T. Costa Jr. \\ Laboratory of Personality and Cognition, National Institute on Aging, NIH, DHHS, Baltimore, MD
}

\section{Abstract}

Aims-Investigating the association between personality traits and smoking status using a comprehensive model of personality, the Five-Factor Model (FFM).

Design-Cross-sectional survey.

Setting-Baltimore, MD, USA.

Participants-Adult-elderly Americans $(n=1638)$.

Measurements-A self-administered survey on cigarette smoking and the Revised NEO Personality Inventory.

Findings-Current-smokers scored higher than never-smokers on Neuroticism and lower on Agreeableness and Conscientiousness; former-smokers scored intermediate on these higher-order dimensions. Neuroticism was related to smoking particularly among individuals with low Conscientiousness, as indicated by an interaction effect between the two factors. There were no differences on Extraversion and Openness to Experience. At the lower-order facet level, smokers were characterized by inability to resist cravings (high Impulsiveness), search for stimulation (high Excitement-seeking), lack of perseverance (low Self-Discipline), and lack of careful consideration of the consequences of their actions (low Deliberation).

Conclusions-At the higher-order factor level, this study replicates and extends previous studies using a comprehensive model of personality (FFM). The greater specificity provided by the facetlevel analysis appears to explain some of the conflicting results in the literature, and the use of an older sample provides insight especially into the former smokers group. Personality research may lead to a deeper understanding of cigarette smoking and can potentially contribute to policies and programs of smoking prevention and cessation.

\section{Keywords}

Smoking; health risk behavior; personality traits; Five-Factor Model; neuroticism; impulsivity; conscientiousness; interaction effect

The World Health Organization (WHO, 2002) identifies tobacco smoking as a major preventable risk factor for disease, disability, and death. Programs of smoking prevention and cessation are based on an understanding of the psychological, social, biological, and pharmacological processes involved in smoking initiation and maintenance (Leventhal \& Cleary 1980). Smoking cessation programs are increasingly concerned with matching interventions to individuals' needs and their stage of change (Velicer et al. 1993, Prochaska et al. 2001). From this perspective, it is important to identify individual difference variables particularly personality traits that increase the risk for cigarette smoking. Understanding the

Address: Antonio Terracciano, Laboratory of Personality and Cognition, National Institute on Aging, NIH, DHHS, 5600 Nathan Shock Drive, Baltimore, MD 21224, USA. Telephone: 410-5588358; Fax: 410-5588108. E-mail: TerraccianoA@grc.nia.nih.gov. 
influence of personality on behavior may improve interventions through public policies and personalized treatment.

Personality traits are enduring dispositions (McCrae \& Costa 2003) and major determinants of behavior (Paunonen 2003). In the last few decades, a growing consensus has supported the Five-Factor Model (FFM, see Digman 1990, Goldberg 1990, John 1990, McCrae \& John 1992, McCrae 2001a, but see Block 1995) as a comprehensive yet manageable taxonomy of traits. Those traits have been shown to be heritable (e.g. Jang et al. 1998) and generalizable across-cultures (McCrae \& Costa 1997, Paunonen et al. 2000, McCrae 2001b, see also Triandis $\&$ Suh 2002). The FFM is a hierarchical model that organizes personality traits into five broad or higher-order factors of Neuroticism (N), Extraversion (E), Openness to Experience (O), Agreeableness (A), and Conscientiousness (C). Each factor is defined by six more specific, lower-order traits, known as facets (see Table 1 for a listing of the 30 facet scales). In this study, the five broad factors as well as the specific facets, were used as a framework to investigate the relationship between smoking and personality.

A large number of studies have examined the relationships between personality traits and cigarette smoking variables. Although the personality differences between smokers and nonsmokers are usually small, they are important considering the large number of people who smoke (World Health Organization 2002). Even a small contribution of personality research may enhance knowledge of smoking behavior and have a clinical impact through the improvement of smoking prevention and cessation programs.

In 1970, Smith reviewed the empirical literature, and despite conflicting data, concluded that smokers were more extraverted, externally oriented, impulsive, and showed more anti-social tendencies/disagreeableness and poorer mental health than non-smokers. Most of the later studies have been conducted on broad traits conceptually related to the stimulating and moodregulating effects of cigarette smoking. Eysenck (1980) argued that individuals high in Extraversion would smoke in search of stimulation, whereas individuals high in Neuroticism would smoke to reduce tension and anxiety (see also Tate, Pomerleau \& Pomerleau 1994). Results across studies are mixed (e.g., McCrae, Costa \& Bosse 1978, Eysenck 1980, Breslau, Kilbey \& Andreski 1993, Arai et al. 1997, Kassel, Stroud \& Paronis 2003), but when differences were found, smokers tended to score higher on Neuroticism and Extraversion compared to those who never smoked. Fewer studies have examined the association of smoking status with other major dimensions of personality. Some studies have found smokers to score higher than non-smokers on Eysenck's Psychoticism (e.g., Spielberger \& Jacobs 1982, Arai et al. 1997, but see Parkes 1984, Breslau, Kilbey \& Andreski 1994), a construct inversely related to Agreeableness and Conscientiousness (McCrae \& Costa 1985, Goldberg \& Rosolack 1994). Smoking is regarded as somewhat antisocial (Eysenck 1980), and, consistent with this view, Smith (1967) found that smokers were rated by their peers as being low on Agreeableness. Vollrath, Knoch and Cassano (1999) found smoking to be inversely related to self-reported Agreeableness. There is evidence that low Conscientiousness is related to health risk behaviors (Booth-Kewley \& Vickers 1994, Vollrath et al. 1999, Trobst et al. 2000, Vollrath \& Torgersen 2002). A remarkable 24-year follow-up study (Kubicka et al. 2001) showed that low Conscientiousness in children, but not Neuroticism or Extraversion, was a predictor of smoking in adulthood. Gilbert (1995) summarized studies subsequent to the review of Smith (1970). Despite some inconsistency he concluded that smokers differed most reliably on Psychoticism (especially impulsivity, antisocial behavior, sensation seeking, and aggression) and Neuroticism. He argued that recent studies found only a weak relationship between smoking and Extraversion, and the role of Openness has not been adequately assessed.

There are several possible explanations for the discrepancies in the literature. The studies conducted span large time periods and involve different countries. Cultural factors and public 
policy influence greatly the prevalence of smoking in the population and in turn the characteristics of smokers (Hughes et al. 1997). Knowledge of the adverse health consequences of smoking and stringent social policy has produced dramatic effects on some groups but not on others (Pomerleau 1997), and US smokers today are likely to be different from the US smokers of a few decades ago, or current smokers in non-Western countries. The inconsistency in the literature may derive also from comparisons of studies that have used different instruments, different methods of classification of smoking status, or different populations sampled. Another possible reason for inconsistency across studies is the broad and heterogeneous nature of the dimensions studied. For example, the FFM characterizes Extraversion as being hierarchically related to six lower-order facets such as Warmth, Gregariousness, Assertiveness, Activity, Excitement Seeking, and Positive Emotions. Among these, only Excitement Seeking is conceptually related to Eysenck's hypothesis and neurochemical evidence that smoking produces central nervous system stimulation (see also Benowitz 1988, Carton, Jouvent \& Widlocher 1994, Stein et al. 1998). Although the six facets tend to covary, each has unique variance and predictive value (Paunonen \& Ashton 2001), and they are not equally represented in all global measures of Extraversion. More consistent results might be obtained if the specific facets were assessed.

Analysis at the level of facets permits the examination of multi-faceted constructs, which could be relevant to understanding smoking behavior. For example, Whiteside and Lynam (2001) point out that four facets from three factors or domains of the Revised NEO Personality Inventory (NEO-PI-R, Costa \& McCrae 1992) define the multi-faceted construct of impulsivity: Impulsiveness, one of the six facets of Neuroticism, refers to the inability to resist cravings and urges; Excitement Seeking, a facet of Extraversion, refers to the tendency to seek excitement and stimulation; low Self-Discipline, a facet of Conscientiousness, refers to the inability to begin and complete a task in the face of boredom and other distractions; and low Deliberation, another facet of Conscientiousness, refers to the tendency to act without considering the consequences (Costa \& McCrae 1992). These facets likely play a role in smoking initiation, maintenance, or cessation, and only analyses at the facet level offer the opportunity to assess their importance.

Even at the global factor level, new analyses might be revealing. Parkes (1984) performed discriminant analyses on Eysenck's dimensions and found interactions between Neuroticism and Psychoticism and between Neuroticism and Extraversion to contribute significantly to the differentiation between smokers and non-smokers. Vollrath and Torgersen (2002) used a typological approach and found that individuals both high in Neuroticism and low in Conscientiousness were disproportionately likely to be smokers. The analysis of interaction effects and the use of a typological approach have the advantage of considering multiple dimensions simultaneously. Examining complex interactions is interesting because the effect of a single personality factor can be intensified, weakened or cancelled by the individual's standing on other factors. In this study we examined the interactive effects between the factors of the FFM, to investigate whether combinations of traits have unique effects. The ten possible pairs from the five factors are also known as personality styles: Neuroticism x Extraversion, style of Well-Being; Neuroticism x Openness, style of Defense; Neuroticism x Agreeableness, style of Anger Control; Neuroticism x Conscientiousness, style of Impulse Control; Extraversion x Openness, style of Interest; Extraversion x Agreeableness, style of Interaction; Extraversion x Conscientiousness, style of Activity; Openness x Agreeableness, style of Attitude; Openness x Conscientiousness, style of Learning; Agreeableness x Conscientiousness, style of Character (Costa \& McCrae 2000).

Another notable feature of this study is the demographics of the sample studied: middle-aged and elderly adults. As a group, these men and women are at low risk of smoking initiation, but at higher (immediate) risk of the adverse effects of smoking on health. Older populations 
include a large proportion of former smokers, a group that cannot be well addressed with a younger sample. Finally, older populations are of interest because they have been less frequently studied.

To summarize, this study examined personality differences between never, former, and current smokers on the five broad factors and 30 specific facets of the FFM. The analyses at the factor level have the potential to replicate and extend previous studies. The analyses at the level of facets can provide a more detailed profile of the smoker groups and potentially resolve inconsistencies in the literature. Finally, interactions between factors were examined to evaluate the effects of combinations of personality traits.

\section{Method}

\section{Sample}

Participants $(N=1638$; age range from 20 to $96, M=60.3, S D=18)$ completed questionnaires as part of the Baltimore Longitudinal Study on Aging (BLSA, Shock et al. 1984). The BLSA is not a probability sample; participation is on a voluntary basis. However, prior studies did show that findings from this sample were consistent with the findings from representative samples (Costa et al. 1986). Most of BLSA participants are highly educated, have high socioeconomic status, and are relatively healthy. For the analyses of this study, participants were divided into three groups, according to smoking status. "Never-smokers" $(n=828,50.5 \%)$ never smoked, or smoked fewer than 100 cigarettes over their entire lifetime. "Formersmokers" ( $n=694,42.4 \%)$ were those who have quit smoking. On average, former-smokers started smoking at age $19(\mathrm{SD}=5.3$, range $=7$ to 56$)$, smoked for 19 years $(\mathrm{SD}=13.5$, range $=0$ to 62 years) and quit 24 years ago ( $\mathrm{SD}=14.9$, range $=1$ to 70 years). "Currentsmokers" ( $n=116,7.1 \%)$ were those who reported smoking at the time of the most recent visit. On average, current-smokers started smoking at age 20 ( $\mathrm{SD}=6.5$, range $=8$ to 44$)$, and have smoked for 29 years ( $\mathrm{SD}=17.6$, range $=0$ to 72 years).

Smoking and personality assessments were both collected during each two-day visit to the Gerontology Research Center, Baltimore, MD, USA. The most recent visit was considered in the cases of multiple assessments. Most participants completed smoking and personality questionnaires on the same day or within 48 hours. About $2.4 \%$ of cases had no personality or smoking data collected during the most recent visit. In those cases the data from the next most recent visit were used (there was on average a two year interval between visits). The data available were collected from 1989 through 2002. The median date of visit was August 1996 for the never-smokers, March 1997 for the former-smokers, and October 1993 for the current smokers. Those dates reflect the decline in the number of US smokers in the 1990s.

There were gender differences in the three groups $\left(\chi^{2}(2)=31, p<.001\right)$. More women were never-smokers ( $22.5 \%$ men vs. $28.1 \%$ women), whereas more men were former-smokers ( $24.9 \%$ men vs. $17.5 \%$ women). Gender differences among the current-smokers were small (3.6\% men vs. $3.5 \%$ women). The groups differed in age $(F(2,1634)=36.7, p<.001)$. The former-smokers $(M=64.2, S D=15.8)$ were older than the never-smokers $(M=58.3, S D=$ $19)$, who were older than the current-smokers $(M=51.5, S D=17.7)$. There were also significant differences in years of education $(F(2,1582)=6.9, p=.001)$. Current-smokers $(M=15.4$, $S D=2.7)$ were significantly less educated than former-smokers $(M=16.2, S D=2.7)$ and neversmokers $(M=16.4, S D=2.4)$. The low percentage of current-smokers, the high percentage of former-smokers, and the pattern observed for gender, age, and education are reasonably in line with the United States population of older individuals with high education (Center for Disease Control 2002). According to the National Health Interview Survey, United States, 2000 (Center for Disease Control 2002), the prevalence of smoking was 9.7\% among the population older than 65 years. The prevalence was also lower among individuals with high education (13.2\% 
among those with an undergraduate degree and $8.4 \%$ among those with a graduate degree) and who are above the poverty level.

\section{Personality Assessment}

The NEO-PI-R (Costa \& McCrae 1992) is a self-report questionnaire consisting of 240 items answered on a five-point Likert scale ranging from strongly disagree to strongly agree. The NEO-PI-R assesses 30 facets, six for each dimension of the FFM. Normative data are used to standardize raw scores into $T$-scores $(M=50, S D=10)$. NEO-PI-R scales have shown longitudinal stability, cross-observer agreement, and convergent and discriminant validity in a large body of studies (Costa \& McCrae 1992).

\section{Statistical Analyses}

All analyses were performed using SPSS 11.0.1. The assumption of homogeneity of variance for the ANOVA was tested using the Levene statistic. No large violations were found and robust statistics produced consistent results. In the major analysis reported in Table 1, Bonferroni correction was performed to evaluate the statistical significance of mean differences among the three groups. Because 35 comparisons were performed, the .05 and .01 significance levels were divided by $35(.05 / 35=.0014 ; .01 / 35=.00029)$. The effect sizes were estimated with $\eta^{2}$. According to Cohen (1998), $\eta^{2}$ values of $.0099, .0588$, and .1379 correspond to small, medium, and large effect sizes, respectively.

\section{Results}

Means (SD) for personality traits for the never, former, and current-smoker groups are reported in Table 1. Analysis of variance (see $F$ values in Table 1) indicates that there were significant differences among groups on Neuroticism, Agreeableness, and Conscientiousness, but no significant differences on Extraversion or Openness factors. Post-hoc tests indicate that current-smokers compared to non-smokers scored significantly higher on Neuroticism and significantly lower on Agreeableness and Conscientiousness, with the difference in Conscientiousness larger than $0.5 S D, d=.6$. Former-smokers showed intermediate scores on the above factors, with significant differences from the other groups on Neuroticism and Conscientiousness. Former-smokers also scored significantly lower than never-smokers in Agreeableness. Additional analyses indicated that individuals who smoked fewer than 100 cigarettes in their lifetime scored intermediate between never and former smokers on Neuroticism, Agreeableness and Conscientiousness, but they were not significantly different from never smokers.

Analyses at the facet level indicate that with the exception of Self-Consciousness, all facets of Neuroticism showed significant differences among smoking status groups. Current-smokers scored higher than the other groups on all facets of Neuroticism, with the largest differences in Impulsiveness. Among the facets of Extraversion, there were significant differences only on Excitement Seeking, with current-smokers scoring higher then never-smokers. There were significant differences on Openness to Values, with current-smokers scoring the highest. There were also significant differences on Straightforwardness, Altruism, and Compliance, with current-smokers scoring lower than never-smokers. There were significant differences among groups on all facets of Conscientiousness, with smokers scoring clearly lower than nonsmokers. The $\eta^{2}$ values are between small and medium effect size (Cohen 1988), which are consistent with previous studies.

ANCOVAs were performed to control for the effect of age and education because smokers were younger and less educated than non-smokers, and there are known maturational changes (McCrae et al. 1999) and effects of education (Costa \& McCrae 1992) on personality traits. 
After controlling for age and education, the differences among groups remained unchanged. There were differences in gender composition in the three groups and there are known sex differences in personality traits (Costa, Terracciano \& McCrae 2001). The present analysis used $T$-scores standardized within gender, thus adjusting for gender effects.

In addition to the above statistical controls, a "design control" was performed, selecting never and former smokers who were sex- and age-matched to the current smokers. To select never and former smokers from the large samples, a random procedure was used when multiple cases matched the characteristic of the current smokers. The resulting samples of never $(\mathrm{n}=116$, age $M=51.5$, range 21 to 89$)$ and former smokers $(n=116$, age $M=51.7$, range 21 to 89 ) matched almost perfectly the sample of current smokers $(n=116$, age $M=51.5$, range 21 to 89). ANOVAs indicated that differences among the sex- and age-matched groups were reasonably consistent with the results obtained with the full sample. In particular, there were significant differences on Neuroticism $(p=.001)$, Agreeableness $(p=.001)$, and Conscientiousness $(p<.001)$, but not on Extraversion and Openness $(p>.05)$. The only notable difference was the non-significant differences on Excitement Seeking in the sex-and-agematched sample.

Vollrath and Torgersen (2002) used a typological approach to examine configurations of personality traits in regard to health risk behaviors. They found that individuals both high in Neuroticism and low in Conscientiousness were disproportionately likely to be smokers. To replicate and extend their study, a stepwise hierarchical discriminant analysis was performed to identify factors and interactions between factors that provide the best discrimination among groups. A two stage hierarchical analysis was adopted, entering first the five factors and then the ten two-way interactions. The interaction terms were represented by the cross-products of the factors (e.g., Neuroticism $\times$ Extraversion). As advocated by Cohen (1978), in the hierarchical approach the two-way interactions are corrected for the effects of the main factors; in other words, they explain variance beyond that explained by the main factors. Three of the five factors, Conscientiousness $(\Lambda=.970, F(2,1635)=25.62, p<.001)$, Agreeableness $(\Lambda=$. $958, F(4,3268)=17.67, p<.001)$, and Neuroticism $(\Lambda=.950, F(6,3266)=14.02, p<.001)$ were found to contribute significantly to the discriminant function. Of all possible interaction terms, only Neuroticism $\times$ Conscientiousness contributed significantly to the discriminant function $\left(\Lambda=.946, F(8,3264)=11.59, p<.001, \eta^{2}=1-\Lambda=.054\right)$. Further analyses showed that the discriminant analysis results were robust across different multivariate methods (e.g., multinomial logistic regression, GLM on dichotomized factors). The interactive effect of Neuroticism and Conscientiousness is illustrated in Figure 1, in which the proportions of never, former, and current smokers are stratified by the Style of Impulse Control (combination of scores on Neuroticism and Conscientiousness; Costa, McCrae \& PAR Staff 2000). The group low in Conscientiousness and high in Neuroticism (under-controlled style) was about two times more likely to be current smokers than the group low in Conscientiousness and low on Neuroticism (relaxed), and was three times more likely to be current smokers than groups high on Conscientiousness and high (over-controlled) or low (directed) on Neuroticism. This suggests that Neuroticism was related to smoking mostly among individuals low on Conscientiousness.

\section{Discussion}

There has been great progress in trait psychology in the past 20 years, with a general consensus on the FFM as a reasonably comprehensive taxonomy of personality traits. A major contribution of the present study is its use of the FFM to investigate the association between cigarette smoking and personality traits. Analyses at the facet level extend knowledge, allow direct tests of hypotheses, and provide insight into the dynamics of cigarette smoking. 
Current-smokers were found to score significantly higher than never-smokers on Neuroticism and significantly lower on Agreeableness and Conscientiousness. Former-smokers showed intermediate scores on these factors, with significant differences from the others groups in Neuroticism and Conscientiousness, suggesting that Neuroticism and Conscientiousness may play a role in both smoking initiation and maintenance/cessation. No differences on overall Extraversion or Openness were observed among groups. These effects remained after controlling for age, education, and sex with a statistical and a design control. At the facet level, all facets of Neuroticism except Self-Consciousness showed significant differences among groups, with the largest differences in Impulsiveness. The smokers' higher scores on Neuroticism facets are consistent with the susceptibility toward psychopathology found in nicotine-dependent smokers (e.g., Breslau et al. 1993). The high score on Neuroticism is also consistent with the view that some individuals use cigarette smoking as self-medication (Khantzian 1997). There is striking evidence (Fowler et al. 1996) that smoking inhibits monoamine oxidase, which breaks down neurotransmitters such as serotonin and dopamine that are implicated in mood regulation. The Fowler et al. study highlights the importance of investigating biological and genetic factors underlying or moderating the association of personality traits and smoking. Possible genetic moderators, especially genes involved with serotonin and dopamine systems, are plausible candidates.

High scores on Neuroticism could be a cause as well as an effect of smoking. Indeed, longitudinal data suggest that high Neuroticism is a risk factor for smoking initiation (Cherry \& Kiernan 1976). Other evidence indicates that nicotine depletion (i.e., time between cigarettes) produces high negative affective states (Costa \& McCrae 1981, Parrott 1998, Picciotto, Brunzell \& Caldarone 2002) and over long periods of time, cigarette smoking may increase the risk of anxiety and depressive disorders (Choi et al. 1997, Wu \& Anthony 1999, Johnson et al. 2000). Consistent with previous studies (Parrott 1998), former-smokers scored lower on Neuroticism compared to current-smokers. It is possible that even before quitting, former-smokers had a lower Neuroticism score compared to individuals who continued to smoke, which may have facilitated quitting: The stress of nicotine withdrawal may be more tolerable to better adjusted people (Hall et al. 1993, Covey, Glassman \& Stetner 1997, Madden et al. 1997). Alternatively, quitting smoking may reduce stress and lower Neuroticism, as some evidence suggests (Parrott 1995, 1998), providing an additional incentive for quitting smoking.

Among the facets of Extraversion, only Excitement-Seeking differed among groups, with current smokers scoring higher than non-smokers. The role of Excitement-Seeking is particularly relevant in light of the stimulating effect of nicotine. However, global Extraversion was unrelated to smoking status, because there were no differences among groups on the other facets. Prior findings suggesting that Extraversion is related to smoking were often obtained using measure of Extraversion that included impulsivity as facet (Eysenck \& Eysenck 1964). Different questionnaires assess Extraversion through different facets and this might explain the literature's inconsistent results regarding the broad Extraversion factor. Another intriguing, although speculative, possibility is that extraverts are more likely to be smokers within populations with a high prevalence of smokers, where smoking is less socially disapproved (Eysenck 1983). Indeed, the association of smoking with Extraversion was found in the US population before 1970-1980 (Smith 1970), but not in the last two decades, whereas the association is still found in countries with a high prevalence of smokers, such as Japan (Arai et al. 1997). An inverse pattern could be argued for Neuroticism.

Considering the social pressure against starting and continuing smoking, the smokers' lower scores on Agreeableness facets are not surprising. Some studies suggest that rebelliousness, a trait closely related to low Agreeableness, contributes to the etiology of cigarette smoking (Stewart \& Livson 1966). Individuals with low scores on Agreeableness are antagonistic, hostile, and intolerant; they have lower needs for social approval and thus are more likely to 
start and continue smoking in spite of the deleterious effect of smoking upon other people (e.g., environmental tobacco smoke or secondhand smoking, negative role models). Among the facets of Conscientiousness, smokers were particularly lower in Self-Discipline and Deliberation, which are related to the impulsivity construct. Lack of persistence, restraint, and dutifulness are likely to play a critical role in the individual's susceptibility to smoking initiation. The same personality characteristics are also likely to undermine efforts in smoking cessation programs. Low Conscientiousness has been associated with other health risk behaviors (see Trobst et al. 2000), and the present study supports the view that Conscientiousness is the strongest personality predictor of health risk behaviors (BoothKewley \& Vickers 1994). It is worth noting that the personality dimension of Conscientiousness, which showed the largest association to smoking behavior in this study, has rarely been considered in previous studies. This finding supports the need for the use of a comprehensive model of personality to avoid the risk of neglecting important correlates of health risk behavior.

Combinations of personality traits (styles or types) have been related to smoking. Vollrath and Torgersen (2002) reported that the Impulsive and Insecure personality types, which are both characterized by low Conscientiousness and high Neuroticism, are more likely to be currentsmokers. Analyses on the present sample are highly consistent with their findings and are somewhat consistent with the Parkes' (1984) findings of an interaction between Neuroticism and Psychoticism but not with the finding of interaction between Neuroticism and Extraversion. The Neuroticism $\times$ Conscientiousness interaction effect illustrates that personality traits can influence behavior in a complex manner. The level of Conscientiousness seems to be a moderator factor in the relationship between Neuroticism and smoking. Neuroticism was related to smoking particularly among individuals with low Conscientiousness, an effect that may have contributed to produce inconsistent results across studies. These data suggest that individuals high on Conscientiousness may not adopt the same maladaptive strategy (i.e., smoking) to deal with high Neuroticism. Of relevance, high Neuroticism and low Conscientiousness defines the Under-controlled style of Impulse Control. Under-controlled individuals are described as being "often at the mercy of their own impulses. They find it difficult and distressing to resist any urge or desire, and they lack self-control to hold their urges in check. As a result, they may act in ways that they know are not in their longterm interests. They may be particularly susceptible to substance abuse and other health risk behaviors" (Costa, McCrae \& PAR Staff 2000).

The findings of the present study have implications for understanding smoking and smoking cessation programs. The high impulsivity of smokers, expressed in their inability to resist cravings, search for stimulation, lack of careful consideration of the consequences of their actions, and their limited self-discipline, suggest that relying only on the individual's resources could be a poor strategy for smoking prevention and cessation. Even with full knowledge of the harmful effects of smoking, individuals with this personality profile may be unable to control their smoking. Data from the WHO confirm that societal pressure in the form of high taxation, restriction in advertising, and interdiction of smoking in public places are more cost effective than programs that rely on the efforts of individual smokers. However, evidence that smokers are not a homogeneous group suggests that a diversity of treatment modalities is necessary. For example, smokers high on Neuroticism might benefit from psychotherapy or antidepressant treatment. A combination of public policy and treatment strategies tailored to the needs of individual smokers is required to reduce the prevalence of cigarette smoking. Potentially important in this regard, is the addition of personality trait profiles to expert-systems interventions for smoking cessation as described by Velicer and Prochaska (1999). Their Pathways to Change System is based upon the Transtheoretical model of change and provides assessments and feedback related to the individuals' needs and readiness to change. Efficacy is evidenced by cessation rates of $22-26 \%$ in a general population. An important and interesting 
aspect of future research is to consider how to integrate individual smoker's personality trait information into population-based intervention programs. Indeed, different treatment options are available, and all seem effective on some individuals but not on others. Personality traits may provide indications of which treatments are more likely to be effective. For example, individuals high on Neuroticism may benefit from psychotherapy or medication or both. Such indications could be based on observational data from former smokers, assessing their personality traits and their successful and unsuccessful ways of quitting. More compelling data would come from assessing personality traits in individuals involved in ongoing cessation treatment programs. In both cases, it would be possible to test whether personality traits affect the success rate of each treatment program.

This study was conducted on an adult-elderly US population, from 1989 to 2002. Although the findings are likely to generalize to the US adult population today, historical and crosscultural differences may shape the association of smoking status with personality traits. As argued by Hughes et al. (1997), the prevalence of smoking is constantly changing, with different trends in different times and cultures. Continuous monitoring of the variables associated with smoking status is essential to addressing this major public health treat.

\section{References}

Arai Y, Hosokawa T, Fukao A, Izumi Y, Hisamichi S. Smoking behaviour and personality: A populationbased study in Japan. Addiction 1997;92:1023-033. [PubMed: 9376772]

Benowitz NL. Pharmacologic aspects of cigarette-smoking and nicotine addiction. New England Journal of Medicine 1988;319:1318-1330. [PubMed: 3054551]

Block J. A Contrarian View of the 5-Factor Approach to Personality Description. Psychological Bulletin 1995;117:187-215. [PubMed: 7724687]

Booth-Kewley S, Vickers RR. Associations between major domains of personality and health behavior. Journal of Personality 1994;62:282-298.

Breslau N, Kilbey MM, Andreski P. Vulnerability to psychopathology in nicotine-dependent smokers: An epidemiologic study of young-adults. American Journal of Psychiatry 1993;150:941-946. [PubMed: 8494073]

Breslau N, Kilbey MM, Andreski P. DSM-III-R Nicotine Dependence in Young-Adults: Prevalence, Correlates and Associated Psychiatric-Disorders. Addiction 1994;89:743-754. [PubMed: 8069175]

Carton S, Jouvent R, Widlocher D. Sensation Seeking, nicotine dependence, and smoking motivation in female and male smokers. Addictive Behaviors 1994;19:219-227. [PubMed: 7942242]

Center for Disease Control. Cigarette smoking among adults: United States, 2000. MMWR Morbidity and Mortality Weekly Report 2002;51:642-645. [PubMed: 12186222]

Cherry N, Kiernan K. Personality scores and smoking behaviour. A longitudinal study. British Journal of Preventive \& Social Medicine 1976;30:123-131. [PubMed: 953376]

Choi WS, Patten CA, Gillin JC, Kaplan RM, Pierce JP. Cigarette smoking predicts development of depressive symptoms among US adolescents. Annals of Behavioral Medicine 1997;19:42-50. [PubMed: 9603677]

Cohen J. Partialed products are interactions; partialed powers are curve components. Psychological Bulletin 1978;85:858-866.

Cohen, J. Statistical power analysis for the behavioral sciences. Hillsdale, New Jersey: Lawrence Erlbaum Associates; 1988.

Costa PT Jr, McCrae RR. Stress, smoking motives, and psychological well-being: The illusory benefits of smoking. Advances in Behaviour Research \& Therapy 1981;3:125-150.

Costa, PT., Jr; McCrae, RR. Revised NEO Personality Inventory (NEO-PI-R) and NEO Five-Factor Inventory (NEO-FFI) professional manual. Odessa, FL: Psychological Assessment Resources; 1992.

Costa, PT., Jr; McCrae, RR. PAR Staff. NEO PI-R interpretive report. NEO Software System. Odessa, FL: Psychological Assessment Resources, Inc; 2000. 
Costa PT Jr, McCrae RR, Zonderman AB, Barbano HE, Lebowitz B, Larson DM. Cross-sectional studies of personality in a national sample: 2 . Stability in neuroticism, extraversion, and openness to experience. Psychology and Aging 1986;1:144-149. [PubMed: 3267391]

Costa PT Jr, Terracciano A, McCrae RR. Gender differences in personality traits across cultures: Robust and surprising findings. Journal of Personality and Social Psychology 2001;81:322-331. [PubMed: 11519935]

Covey LS, Glassman AH, Stetner F. Major depression following smoking cessation. American Journal of Psychiatry 1997;154:263-265. [PubMed: 9016279]

Digman JM. Personality Structure: Emergence of the Five-Factor Model. Annual Review of Psychology 1990;41:417-440.

Eysenck, HJ. The causes and effects of smoking. Beverly Hills, California: Sage; 1980.

Eysenck HJ. Smoking, personality and reasons for smoking. Psychological Medicine 1983;13:447-448. [PubMed: 6878531]

Eysenck, HJ.; Eysenck, SBG. Manual of the Eysenck Personality Inventory. London: University Press; 1964.

Fowler JS, Volkow ND, Wang GJ, Pappas N, Logan J, Shea C, Alexoff D, MacGregor RR, Schlyer DJ, Zezulkova I, Wolf AP. Brain monoamine oxidase A inhibition in cigarette smokers. Proceedings of the National Academy of Sciences of the United States of America 1996;93:14065-14069. [PubMed: 8943061]

Gilbert, DG. Smoking: Individual differences, psychopathology, and emotion. Washington DC: Taylor \& Francis; 1995.

Goldberg LR. An Alternative Description of Personality: The Big Five Factor Structure. Journal of Personality and Social Psychology 1990;59:1216-1229. [PubMed: 2283588]

Goldberg, LR.; Rosolack, TK. The Big Five factor structure as an integrative framework: An empirical comparison with Eysenck's P-E-N model. In: Halverson, CF.; Kohnstamm, GA.; Martin, RP., editors. The developing structure of temperament and personality from infancy to adulthood. Hillsdale, NJ: Lawrence Erlbaum Associates; 1994. p. 7-35.

Hall SM, Munoz RF, Reus VI, Sees KL. Nicotine, negative affect, and depression. Journal of Consulting and Clinical Psychology 1993;61:761-767. [PubMed: 7902368]

Hughes JR, Giovino GA, Klevens RM, Fiore MC. Assessing the generalizability of smoking studies. Addiction 1997;92:469-472. [PubMed: 9177068]

Jang KL, McCrae RR, Angleitner A, Riemann R, Livesley WJ. Heritability of facet-level traits in a crosscultural twin sample: Support for a hierarchical model of personality. Journal of Personality and Social Psychology 1998;74:1556-1565. [PubMed: 9654759]

John, OP. The Big Five factor taxonomy: Dimensions of personality in the natural language and in questionnaires. In: Pervin, LA., editor. Handbook of personality: Theory and research. New York: Guilford Press; 1990. p. 66-100.

Johnson JG, Cohen P, Pine DS, Klein DF, Kasen S, Brook JS. Association between cigarette smoking and anxiety disorders during adolescence and early adulthood. Jama-Journal of the American Medical Association 2000;284:2348-2351.

Kassel JD, Stroud LR, Paronis CA. Smoking, stress, and negative affect: Correlation, causation, and context across stages of smoking. Psychological Bulletin 2003;129:270-304. [PubMed: 12696841]

Khantzian EJ. The self-medication hypothesis of substance use disorders: A reconsideration and recent applications. Harvard Review of Psychiatry 1997;4:231-244. [PubMed: 9385000]

Kubicka L, Matejcek Z, Dytrych Z, Roth Z. IQ and personality traits assessed in childhood as predictors of drinking and smoking behaviour in middle-aged adults: a 24- year follow-up study. Addiction 2001;96:1615-1628. [PubMed: 11784458]

Leventhal H, Cleary PD. The smoking problem - a review of the research and theory in behavioral risk modification. Psychological Bulletin 1980;88:370-405. [PubMed: 7422752]

Madden PAF, Bucholz KK, Dinwiddie SH, Slutske WS, Bierut LJ, Statham DJ, Dunne MP, Martin NG, Heath AC. Nicotine withdrawal in women. Addiction 1997;92:889-902. [PubMed: 9293047]

McCrae RR. 5 years of progress: A reply to Block. Journal of Research in Personality 2001a;35:108113. 
McCrae RR. Trait psychology and culture: Exploring intercultural comparisons. Journal of Personality 2001b;69:819-846. [PubMed: 11767820]

McCrae RR, Costa PT Jr. Comparison of EPI and Psychoticism scales with measures of the Five-Factor Model of personality. Personality and Individual Differences 1985;6:587-597.

McCrae RR, Costa PT Jr. Personality trait structure as a human universal. American Psychologist 1997;52:509-516. [PubMed: 9145021]

McCrae, RR.; Costa, PT, Jr. Personality in adulthood: A Five-Factor Theory perspective. New York: Guilford Press; 2003.

McCrae RR, Costa PT Jr, Bosse R. Anxiety, extraversion and smoking. British Journal of Social \& Clinical Psychology 1978;17:269-273. [PubMed: 687883]

McCrae RR, Costa PT Jr, de Lima MP, Simões A, Ostendorf F, Angleitner A, Maruđiã I, Bratko D, Caprara GV, Barbaranelli C, Chae JH, Piedmont RL. Age differences in personality across the adult life span: Parallels in five cultures. Developmental Psychology 1999;35:466-477. [PubMed: 10082017]

McCrae RR, John OP. An introduction to the Five-Factor Model and its applications. Journal of Personality 1992;60:175-215. [PubMed: 1635039]

Parkes KR. Smoking and the Eysenck personality dimensions: An interactive model. Psychological Medicine 1984;14:825-834. [PubMed: 6545416]

Parrott AC. Smoking cessation leads to reduced stress, but why. International Journal of the Addictions 1995;30:1509-1516. [PubMed: 8530219]

Parrott AC. Nesbitt's paradox resolved? Stress and arousal modulation during cigarette smoking. Addiction 1998;93:27-39. [PubMed: 9624709]

Paunonen SV. Big five factors of personality and replicated predictions of behavior. Journal of Personality and Social Psychology 2003;84:411-424. [PubMed: 12585813]

Paunonen SV, Ashton MC. Big five factors and facets and the prediction of behavior. Journal of Personality and Social Psychology 2001;81:524-539. [PubMed: 11554651]

Paunonen SV, Zeidner M, Engvik HA, Oosterveld P, Maliphant R. The nonverbal assessment of personality in five cultures. Journal of Cross-Cultural Psychology 2000;31:220-239.

Picciotto MR, Brunzell DH, Caldarone BJ. Effect of nicotine and nicotinic receptors on anxiety and depression. Neuroreport 2002;13:1097-1106. [PubMed: 12151749]

Pomerleau CS. Co-factors for smoking and evolutionary psychobiology. Addiction 1997;92:397-408. [PubMed: 9177061]

Prochaska JO, Velicer WF, Fava JL, Rossi JS, Tsoh JY. Evaluating a population-based recruitment approach and a stage- based expert system intervention for smoking cessation. Addictive Behaviors 2001;26:583-602. [PubMed: 11456079]

Shock, NW.; Greulich, RC.; Andres, R.; Arenberg, D.; Costa, PT., Jr; Lakatta, EG.; Tobin, JD. Normal human aging: The Baltimore Longitudinal Study of Aging (NIH Publication No. 84-2450). Bethesda, MD: National Institutes of Health; 1984.

Smith GM. Personality correlates of cigarette smoking in students of college age. Annals of the New York Academy of Sciences 1967;142:308-321.

Smith, GM. Personality and smoking: A review of the empirical literature. In: Hunt, WA., editor. Learning mechanisms in smoking. Chicago: Aldine Publishing Company; 1970. p. 42-61.

Spielberger CD, Jacobs GA. Personality and smoking-behavior. Journal of Personality Assessment 1982;46:396-403. [PubMed: 7120020]

Stein EA, Pankiewicz J, Harsch HH, Cho JK, Fuller SA, Hoffmann RG, Hawkins M, Rao SM, Bandettini PA, Bloom AS. Nicotine-induced limbic cortical activation in the human brain: A functional MRI study. American Journal of Psychiatry 1998;155:1009-1015. [PubMed: 9699686]

Stewart L, Livson N. Smoking and rebelliousness: A longitudinal study from childhood to maturity. Journal of Consulting Psychology 1966;30:225-229. [PubMed: 5933618]

Tate JC, Pomerleau CS, Pomerleau OF. Pharmacological and nonpharmacological smoking motives - a replication and extension. Addiction 1994;89:321-330. [PubMed: 8173502]

Triandis HC, Suh EM. Cultural influences on personality. Annual Review of Psychology 2002;53:133160. 
Trobst KK, Wiggins JS, Costa PT Jr, Herbst JH, McCrae RR, Masters HL. Personality psychology and problem behaviors: HIV risk and the five-factor model. Journal of Personality 2000;68:1233-1252. [PubMed: 11130739]

Velicer WF, Prochaska JO. An expert system intervention for smoking cessation. Patient Education and Counseling 1999;36:119-129. [PubMed: 10223017]

Velicer WF, Prochaska JO, Bellis JM, Diclemente CC, Rossi JS, Fava JL, Steiger JH. An expert system intervention for smoking cessation. Addictive Behaviors 1993;18:269-290. [PubMed: 8342440]

Vollrath M, Knoch D, Cassano L. Personality, risky health behaviour, and perceived susceptibility to health risks. European Journal of Personality 1999;13:39-50.

Vollrath M, Torgersen S. Who takes health risks? A probe into eight personality types. Personality and Individual Differences 2002;32:1185-1197.

Whiteside SP, Lynam DR. The Five Factor Model and impulsivity: using a structural model of personality to understand impulsivity. Personality and Individual Differences 2001;30:669-689.

World Health Organization. The World Health Report 2002 -- Reducing risks, promoting healthy life. Geneva: World Health Organization; 2002.

Wu LT, Anthony JC. Tobacco smoking and depressed mood in late childhood and early adolescence. American Journal of Public Health 1999;89:1837-1840. [PubMed: 10589312] 


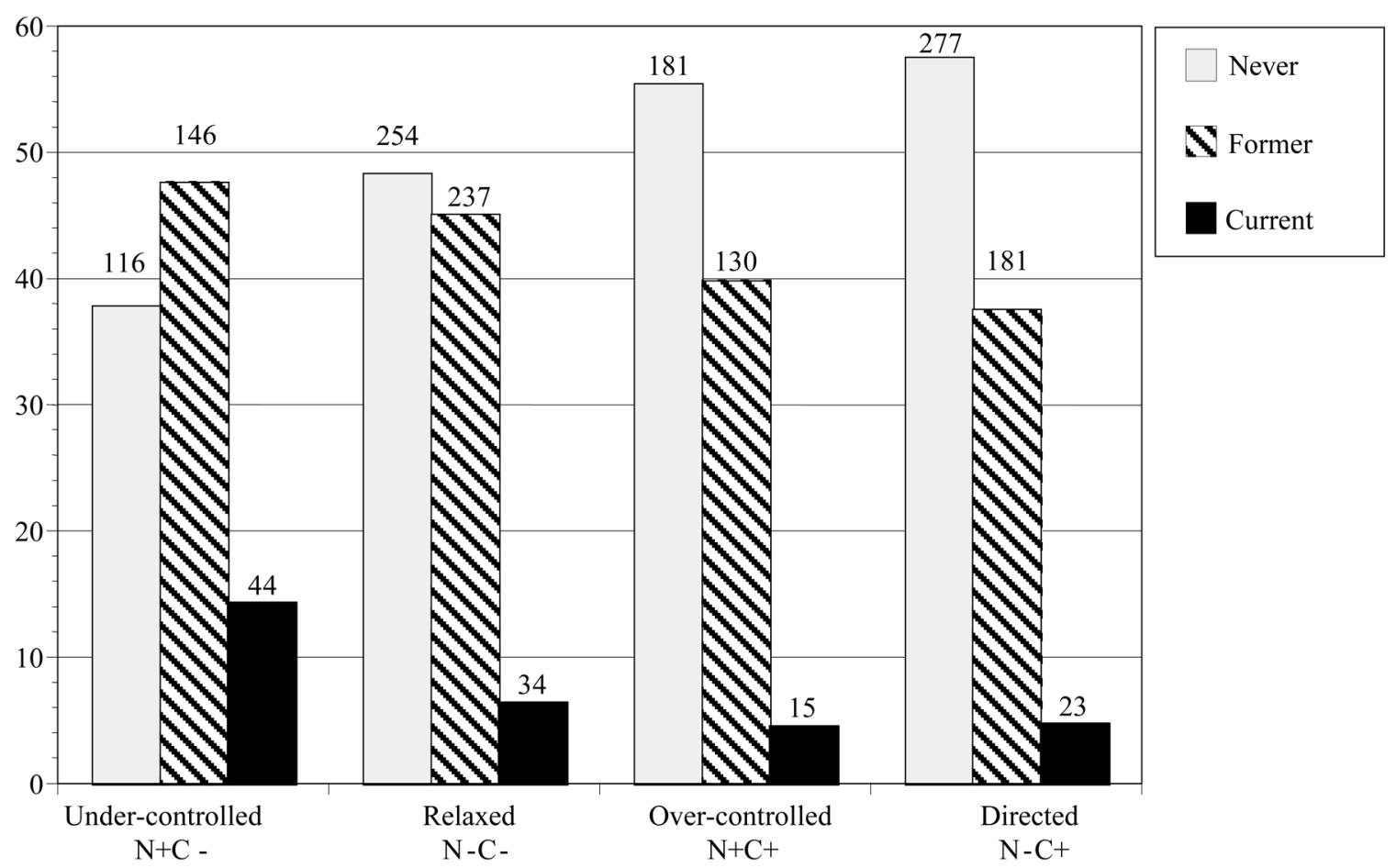

Figure 1. Proportion of smokers in impulse control style groups. Neuroticism $\times$ Conscientiousness interaction

The four impulse control style groups were determined by scores on Neuroticism $(\mathrm{N})$ and Conscientiousness $(C)$. The sample was split at the mean normative value $(M=50)$, and the sign + and - following $\mathrm{N}$ or $\mathrm{C}$ indicates scores above and below the mean, respectively. For example, the Under-controlled $(\mathrm{N}+\mathrm{C}-$ ) group has high scores on Neuroticism and low on Conscientiousness. 


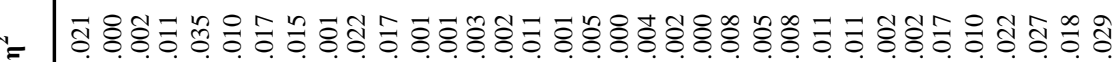

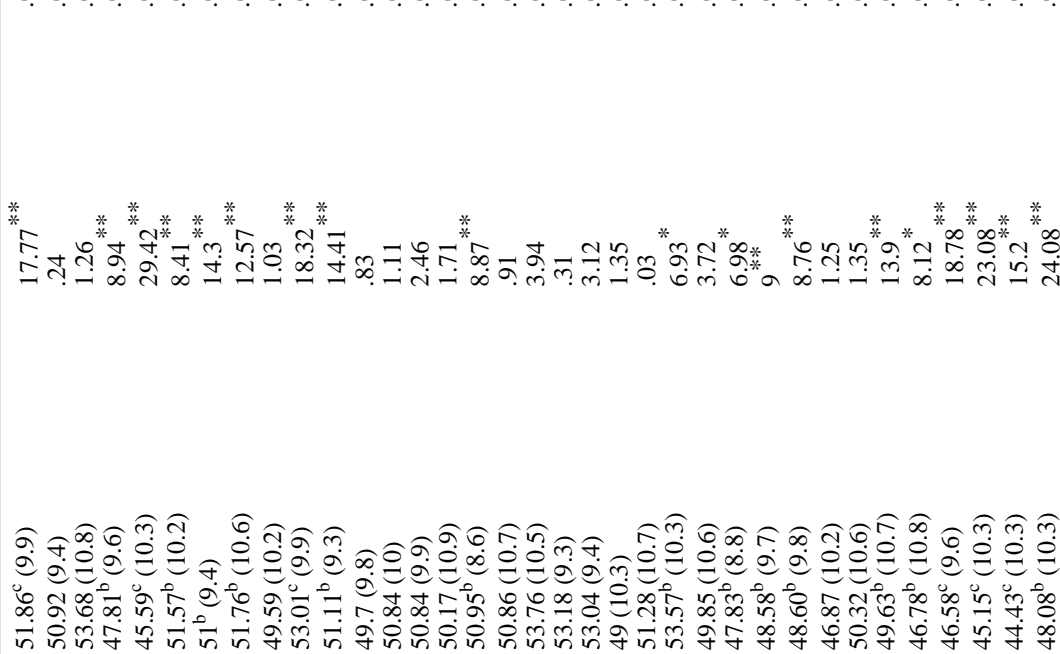

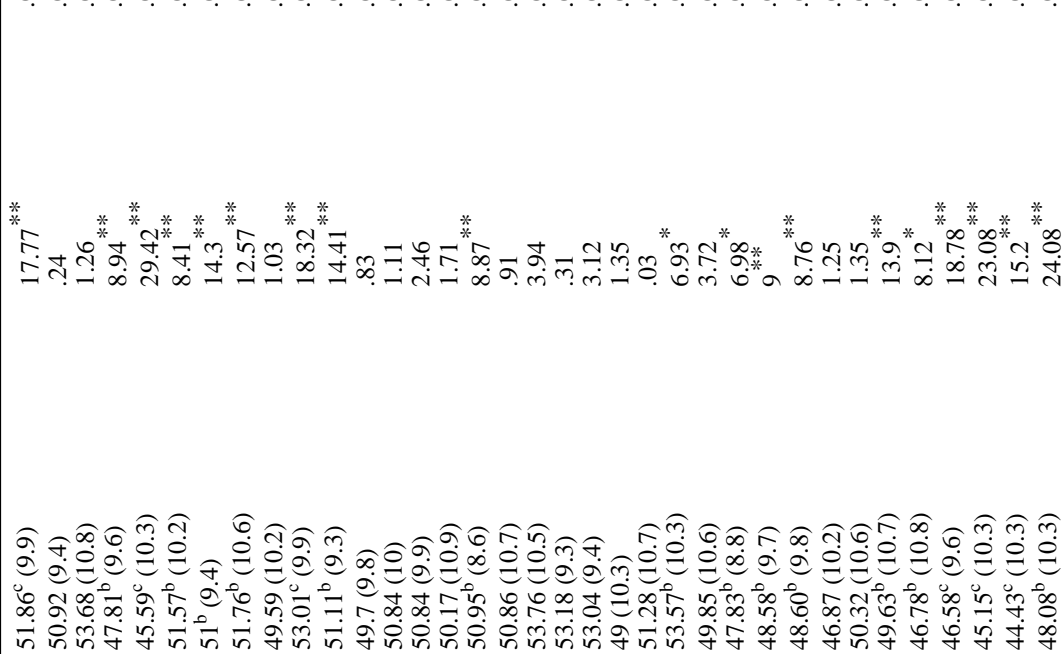

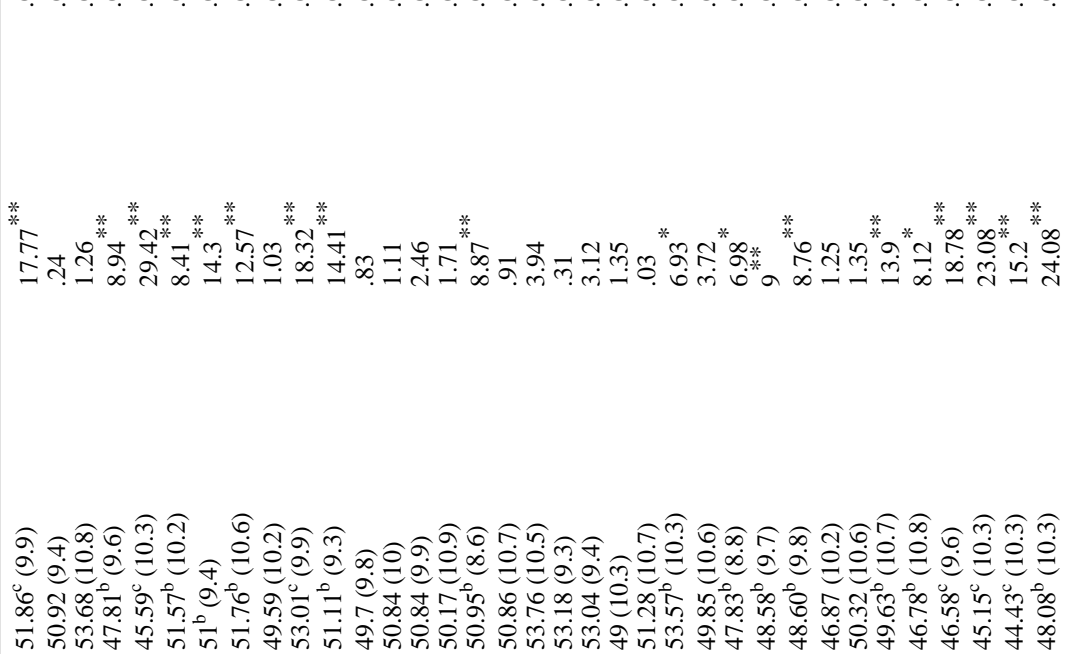

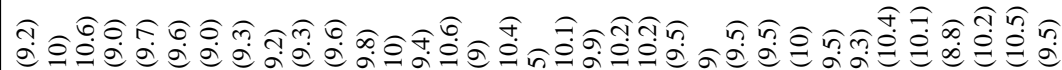

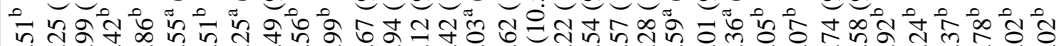

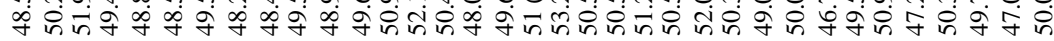

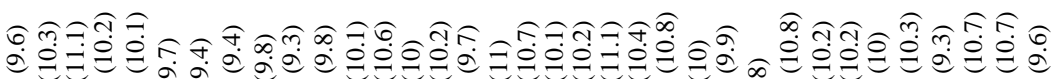

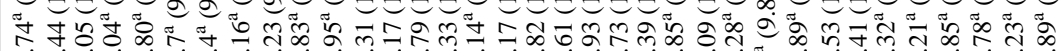

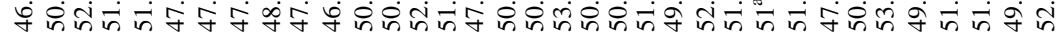

